\title{
Activity-Dependent Intracellular Acidification Correlates with the Duration of Seizure Activity
}

\author{
Zhi-Qi Xiong, ${ }^{1}$ Peter Saggau, ${ }^{2}$ and Janet L. Stringer ${ }^{1,2}$ \\ ${ }^{1}$ Department of Pharmacology and 2Division of Neuroscience, Baylor College of Medicine, Houston, Texas 77030
}

Synchronized neuronal activity (seizures) can appear in the presence or absence of synaptic transmission. Mechanisms of seizure initiation in each of these conditions have been studied, but relatively few studies have addressed seizure termination. In particular, how are seizures terminated in the absence of synaptic activity where there is no loss of excitatory drive or augmentation of inhibitory inputs? We have studied dynamic activity-dependent changes of intracellular $\mathrm{pH}$ in the absence of synaptic transmission using the fluorescent $\mathrm{pH}$ indicator carboxylseminaphthorhodafluo-1. During epileptiform activity we observed intracellular acidification, whereas between seizures the intracellular $\mathrm{pH}$ recovered. Experimental conditions that shortened the epileptiform discharge correlated with more rapid intracellular acidification. On the other hand, experimental manipulation of intracellular $\mathrm{pH}$ altered the duration of the seizure discharge, with acidification resulting in early termination of the epileptiform activity. These data show a direct relationship between the level of intracellular acidification and the duration of the seizures, suggesting that an intracellular $\mathrm{pH}$ dependent process can terminate nonsynaptic neuronal synchronization.

Key words: intracellular $\mathrm{pH}$; seizure termination; dentate gyrus; SNARF-1; hippocampus; neuronal synchronization
Epilepsy is characterized by the periodic and unpredictable occurrence of seizures, which are clinically defined as transient behavioral changes attributable to the synchronous and rhythmic firing of populations of neurons in the CNS. The cellular mechanisms involved in the generation and termination of seizures are not well understood. Much basic research has focused on the mechanisms of seizure initiation. Relatively few studies have addressed how seizures terminate (Konnerth et al., 1986; Spencer and Spencer, 1996; Bragin et al., 1997). Understanding factors critical for terminating an ongoing seizure may lead to more effective treatment of epilepsy.

Neuronal activity elicits substantial changes in extracellular and intracellular $\mathrm{pH}$ in both pathological states and during normal brain function (Chesler and Kaila, 1992; Zhan et al., 1998; Tong and Chesler, 1999). During seizure activity neurons accumulate $\mathrm{H}^{+}$, resulting in acidification of the intracellular space. The $\mathrm{pH}$ of the extracellular space also decreases during seizure activity, often after a transient alkaline shift (Siesj $\div$ et al., 1985; Tomlinson et al., 1992; Velisek et al., 1994; de Curtis et al., 1998; Gutschmidt et al., 1999). The physiological significance of these $\mathrm{pH}$ shifts during seizure activity is not known. On the basis of the marked $\mathrm{pH}$ sensitivity of many ion channels, enzymes, and even receptors (Tang et al., 1990; Gottfried and Chesler, 1994; Tombaugh and Somjen, 1996; Baukrowitz et al., 1999; Kiss and Korn, 1999; Qu et al., 1999; Vincent et al., 1999), it has been suggested that $\mathrm{pH}$ shifts associated with neuronal activity serve as local

\footnotetext{
Received Sept. 15, 1999; revised Nov. 8, 1999; accepted Nov. 24, 1999.

This work was supported by National Institutes of Health Grants NS01784 to J.L.S. and NS33147 to P.S. We thank Drs. Eugene L. Roberts Jr for advice on using SNARF-1 for intracellular $\mathrm{pH}$ measurements in slices, Jing Qian for assistance with the optical recording and data analysis, and Saurabh R. Sinha for advice on the indicator loading.

Correspondence should be addressed to Dr. Janet L. Stringer, Department of Pharmacology, Baylor College of Medicine, One Baylor Plaza, Houston, TX 77030. E-mail: janets@bcm.tmc.edu.

Copyright (C) 2000 Society for Neuroscience $\quad 0270-6474 / 00 / 201290-07 \$ 15.00 / 0$
}

feedback signals (Ransom, 1992; Gottfried and Chesler, 1994; Tombaugh and Somjen, 1996). There are a few studies analyzing the interaction of extracellular $\mathrm{pH}$ and epileptiform activity, but data correlating intracellular $\mathrm{pH}\left(\mathrm{pH}_{\mathrm{i}}\right)$ and neuronal activity are still missing (Chesler and Kaila, 1992; Velisek et al., 1994; Bonnet et al., 1998; de Curtis et al., 1998).

The currently available methods for measuring $\mathrm{pH}_{\mathrm{i}}$ include pH-sensitive microelectrodes, ${ }^{31} \mathrm{P}$ NMR spectroscopy, and pH-sensitive fluorescence probes (Tsien, 1989). We used carboxylseminaphthorhodafluo-1 (SNARF-1), a single-excitation, dual-emission fluorescent $\mathrm{pH}$ indicator (Tsien, 1989; MullerBorer et al., 1998; Roberts, 1999), to study the interaction between $\mathrm{pH}_{\mathrm{i}}$ and seizure onset and termination. Fluorescence microscopy with $\mathrm{pH}$-sensitive fluorophores allows $\mathrm{pH}_{\mathrm{i}}$ changes to be measured with temporal and spatial resolutions that surpass microelectrodes or NMR, respectively (Muller-Borer et al., 1998). We chose an in vitro model of nonsynaptic seizure activity in the dentate gyrus, induced by perfusing hippocampal slices with a low-Ca ${ }^{2+}$, high-K ${ }^{+}$solution. The epileptiform activity consists of bursts of large-amplitude population spikes, termed field bursts (Schweitzer et al., 1992; Pan and Stringer, 1996). These field bursts persist in the presence of blockers of both excitatory and inhibitory neurotransmission (Schweitzer et al., 1992). The spontaneous field bursts recur in a regular pattern, are of long duration, and are associated with extracellular ionic changes. These features provide a well suited in vitro model to study the relationship of changes in $\mathrm{pH}_{\mathrm{i}}$ and the epileptiform discharges.

\section{MATERIALS AND METHODS}

Preparation of hippocampal slices and solutions. Transverse hippocampal slices $(350-400 \mu \mathrm{m})$ were prepared from Sprague Dawley rats $(28-35 \mathrm{~d}$ old) as described (Pan and Stringer, 1996). All experimental procedures were approved by the Animal Research Committee of Baylor College of Medicine. Brain slices were stored in artificial CSF (ACSF; in $\mathrm{mM}$ ): $\mathrm{NaCl} 127, \mathrm{KCl} 2, \mathrm{MgSO}_{4} 1.5, \mathrm{KH}_{2} \mathrm{PO}_{4} 1.1, \mathrm{NaHCO}_{3} 26, \mathrm{CaCl}_{2}$ 2, and D-glucose 10, saturated with $95 \% \mathrm{O}_{2}$ and $5 \% \mathrm{CO}_{2}$ to maintain a constant $\mathrm{pH}$ of 7.38. Slices were allowed to recover for $1 \mathrm{hr}$ from their dissection 
before indicator loading. Field bursts were induced by switching the perfusing solution to ACSF with 0 added $\mathrm{Ca}^{2+}$ and $8 \mathrm{mM} \mathrm{K}^{+}$. When sodium propionate or ammonium chloride was added to the perfusing solution, the $\mathrm{NaCl}$ concentration was reduced by equimolar amounts. For local application of acidic medium, 0 added $\mathrm{Ca}^{2+}$ and $8 \mathrm{mM} \mathrm{K}^{+}$medium was acidified by $\mathrm{HCl}$ to $\mathrm{pH} 6.0$ and was applied locally by leakage from a glass pipette (tip diameter, 2-3 $\mu \mathrm{m}$ ) lowered into the slice.

SNARF-1 loading. The AM of the $\mathrm{pH}$ indicator SNARF-1 $(50 \mu \mathrm{g})$ was dissolved in $20 \mu \mathrm{l}$ of DMSO containing $10 \%$ pluronic acid (w/w). The dissolved indicator was further diluted by $2 \mathrm{ml}$ of ACSF, giving a final concentration of SNARF-1 AM of $40 \mu \mathrm{M}$. This solution, with four or five brain slices, was then put into a $35 \mathrm{~mm}$ Petri dish, which served as the loading chamber. The dish was then covered and placed in a $30^{\circ} \mathrm{C}$ water bath for $3 \mathrm{hr}$. The membrane-permeable indicator is taken up into cells where it is hydrolyzed by an endogenous esterase. The resulting free acid is retained in the cells.

Optical recording. After indicator loading, brain slices were placed for 5-10 min in a large volume $(200 \mathrm{ml})$ of ACSF, equilibrated with $\mathrm{O}_{2}$ and $\mathrm{CO}_{2}$, to remove indicator from the extracellular space. Individual slices were then placed in the interface chamber mounted on an upright epifluorescence microscope (Zeiss) and perfused with ACSF for $30 \mathrm{~min}$. A tungsten lamp (100 W; Osram Sylvania) driven by a stabilized power supply was used as the light source. To prevent condensation from the humidified atmosphere on the objective, we externally heated the objective to $\sim 45^{\circ} \mathrm{C}$. An area of $80-120 \mu \mathrm{m}$ in diameter in the cell body layer of the dentate gyrus was illuminated at $480 \pm 15 \mathrm{~nm}$. SNARF-1 is a dual-emission indicator, so fluorescence was collected simultaneously at $660 \pm 40$ and $580 \pm 40 \mathrm{~nm}$ by two custom-made photodetectors, once every $6 \mathrm{sec}$. Autofluorescence was acquired from an unstained slice in the chamber before each experiment. The SNARF-1 fluorescence ratio (R660/580) was determined after autofluorescence (AF) was subtracted at each emission wavelength as follows: $R 660 / 580=\left(F 660-F 660_{\mathrm{AF}}\right) /$ $\left(F 580-F 580_{\mathrm{AF}}\right)$. In addition to compensating for instrumental factors (i.e., illumination intensity and indicator loading), this ratiometric technique removes activity-dependent light scattering from the brain slice.

$p H$ calibration. Calibration of the obtained SNARF-1 fluorescence ratio was performed using the nigericin and high- $\mathrm{K}^{+}$method (Boyarsky et al., 1988). Briefly, the indicator-loaded slices were exposed to $143 \mathrm{~mm}$ $\mathrm{K}^{+}$solutions of varying extracellular $\mathrm{pH}$ values $(6.33,6.46,6.72,6.85$, $6.97,7.07,7.15,7.28$, and 7.44), containing the $\mathrm{K}^{+}$and $\mathrm{H}^{+}$ionophore nigericin $(5 \mu \mathrm{g} / \mathrm{ml})$. When internal and external $\mathrm{K}^{+}$concentrations are equal, then the intracellular $\mathrm{pH}$ is the same value as the extracellular $\mathrm{pH}$ (Boyarsky et al., 1988). After equilibration (30 min at each point), the relationship between the fluorescence ratio and $\mathrm{pH}$ was fitted by the following equation, in which $R$ was the fluorescence ratio of $660 \mathrm{~nm} / 580$ $\mathrm{nm}: \mathrm{pH}=7.5 \exp \left(-3.2 \mathrm{e}^{-2.8 \mathrm{R}}\right)$. Although this calibration method, which uses living tissue, closely mimics the experimental conditions, there may be errors in the absolute $\mathrm{pH}$ values. During an actual experiment, fluorescence was measured from a population of cells including glia and neurons and conceivably also from the damaged cells at the surface of the brain slice. In contrast, during calibration, the nigericin and high- $\mathrm{K}^{+}$ solution forces the $\mathrm{pH}$ of the intracellular compartments of all cells to equilibrate with the bath $\mathrm{pH}$. So, the difference in $\mathrm{pH}$ between different cell types or even different compartments in a single cell is not mimicked by the calibration method used, making the absolute values for the $\mathrm{pH}$ measurements estimates.

Electrophysiological stimulation and recording. Extracellular recording electrodes were made of microfilament capillary thin-walled glass $(0.9$ $\mathrm{mm}$ inner diameter; $1.2 \mathrm{~mm}$ outer diameter; A-M Systems) that was pulled on a micropipette puller (P-87; Sutter Instrument Company) and filled with $2 \mathrm{M} \mathrm{NaCl}$, resulting in impedances between 4 and $10 \mathrm{M} \Omega$. The electrodes were placed in the dentate cell body layer $\sim 200 \mu \mathrm{m}$ from the optical recording site to avoid possible interference of light reflection from the electrode glass with optical signals. The extracellular field potentials were amplified and displayed on a chart recorder (AstroMed). For antidromic stimulation, a bipolar tungsten electrode was positioned in the hilar region (600-800 $\mu \mathrm{A} ; 0.3 \mathrm{msec}$ biphasic).

Materials. SNARF-1 AM, pluronic acid, and nigericin were from Molecular Probes (Eugene, OR). All other reagents were from Sigma (St. Louis, MO).

\section{RESULTS}

$\mathrm{pH}_{\mathrm{i}}$ was measured quantitatively in the dentate gyrus of hippocampal slices using the $\mathrm{pH}$ indicator SNARF-1. The values of resting $\mathrm{pH}_{\mathrm{i}}$ in normal $\mathrm{ACSF}$ ranged from 6.93 to $7.18(n=10)$.
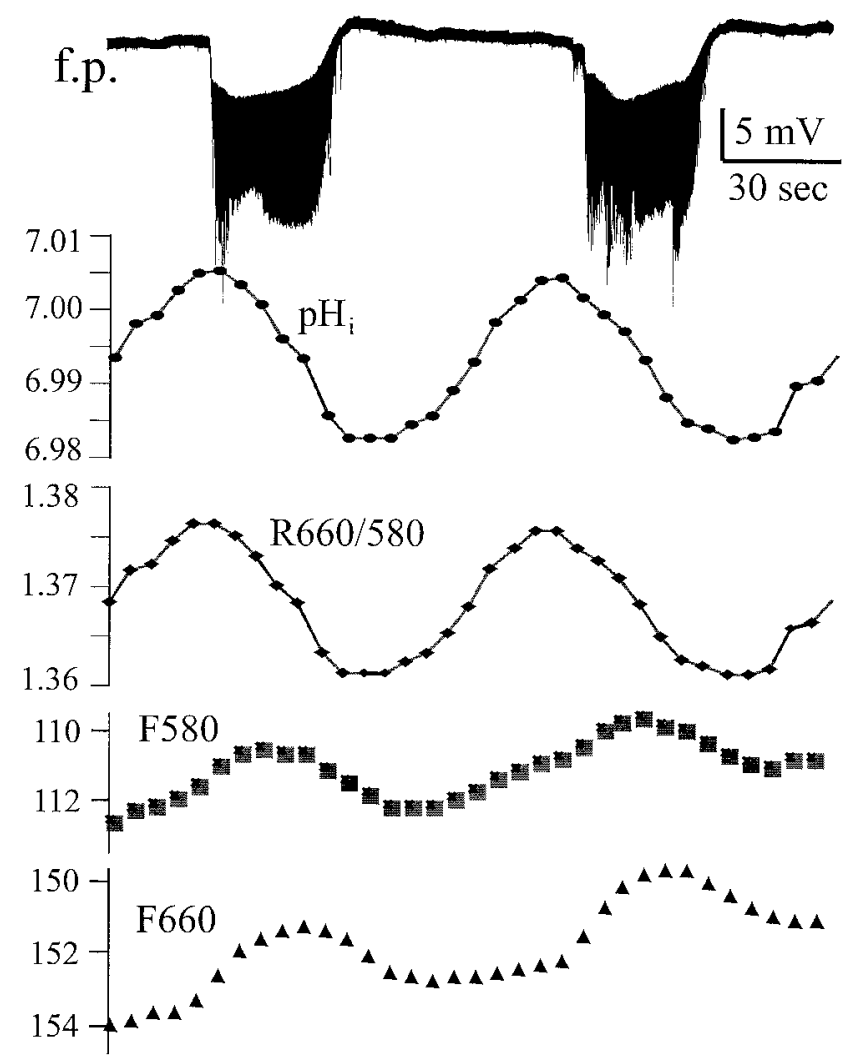

Figure 1. $\mathrm{pH}_{\mathrm{i}}$ changes correlate with spontaneous field bursts in the dentate gyrus. Simultaneous field potentials (f.p.; top trace) and SNARF-1 fluorescence emission recordings from the dentate gyrus of a hippocampal slice (bottom recordings) are illustrated. The spontaneous field bursts appeared in a regular pattern. Fluorescence intensities $(100 \times)$ were acquired at $660 \pm 40 \mathrm{~nm}(\boldsymbol{\Delta})$ and $580 \pm 40 \mathrm{~nm}(\boldsymbol{\square})$. Autofluorescence was acquired from an unstained control slice, and corresponding ratios with autofluorescence subtracted are shown $(R 660 / 580 ; \diamond)$. Titration curves of the ratio versus $\mathrm{pH}$ were calculated and used to convert the fluorescence ratios to $\mathrm{pH}(\bullet)$.

Switching the perfusion solution to 0 added $\mathrm{Ca}^{2+}$ and $8 \mathrm{mM} \mathrm{K}^{+}$ induced an intracellular acidification of $<0.03 \mathrm{pH}$ units that lasted for 5-10 min. After this initial acidification, the $\mathrm{pH}_{\mathrm{i}}$ recovered to the resting values over the next $20 \mathrm{~min}(n=5)$. Prolonged perfusion $\left(>1 \mathrm{hr}\right.$ ) with 0 added $\mathrm{Ca}^{2+}$ and $8 \mathrm{mM} \mathrm{K}^{+}$medium caused periodic spontaneous field bursts in $90 \%$ of the hippocampal slices tested. During the spontaneous activity, the $\mathrm{pH}_{\mathrm{i}}$ showed a biphasic response (Fig. 1). Each field burst was associated with intracellular acidification, reaching the lowest value at the end of each field burst. After termination of the field burst, the $\mathrm{pH}_{\mathrm{i}}$ slowly recovered. The average magnitude of the change in $\mathrm{pH}_{\mathrm{i}}$ during the field bursts was $0.025 \pm 0.003 \mathrm{pH}$ units ( $n=18$ slices). The measured change in $\mathrm{pH}$ represents the average from a population of cells, including nonbursting cells (e.g., glia and damaged cells), which may dilute, or reduce, the magnitude of the measured $\mathrm{pH}$ shift. Therefore, the magnitude of the actual intracellular $\mathrm{pH}$ changes within the bursting neurons is most likely larger than that recorded in these experiments. In support of this possibility, we recorded larger $\mathrm{pH}$ changes (up to $0.05 \mathrm{pH}$ units) in some slices when the illuminated recording area in the cell body layer was smaller than average. However, smaller recording areas had higher noise levels, needed a higher intensity for excitation, and had a faster bleaching of the fluorescence, making the useful recording time shorter. 
Figure 2. The duration of the spontaneous field bursts correlates with acidification of the $\mathrm{pH}_{\mathrm{i}}$. In some brain slices (20\%), an occasional spontaneous field burst started before the $\mathrm{pH}_{\mathrm{i}}$ had recovered. Two representative examples are shown (marked by *). In these cases the duration of the field burst was always shorter.
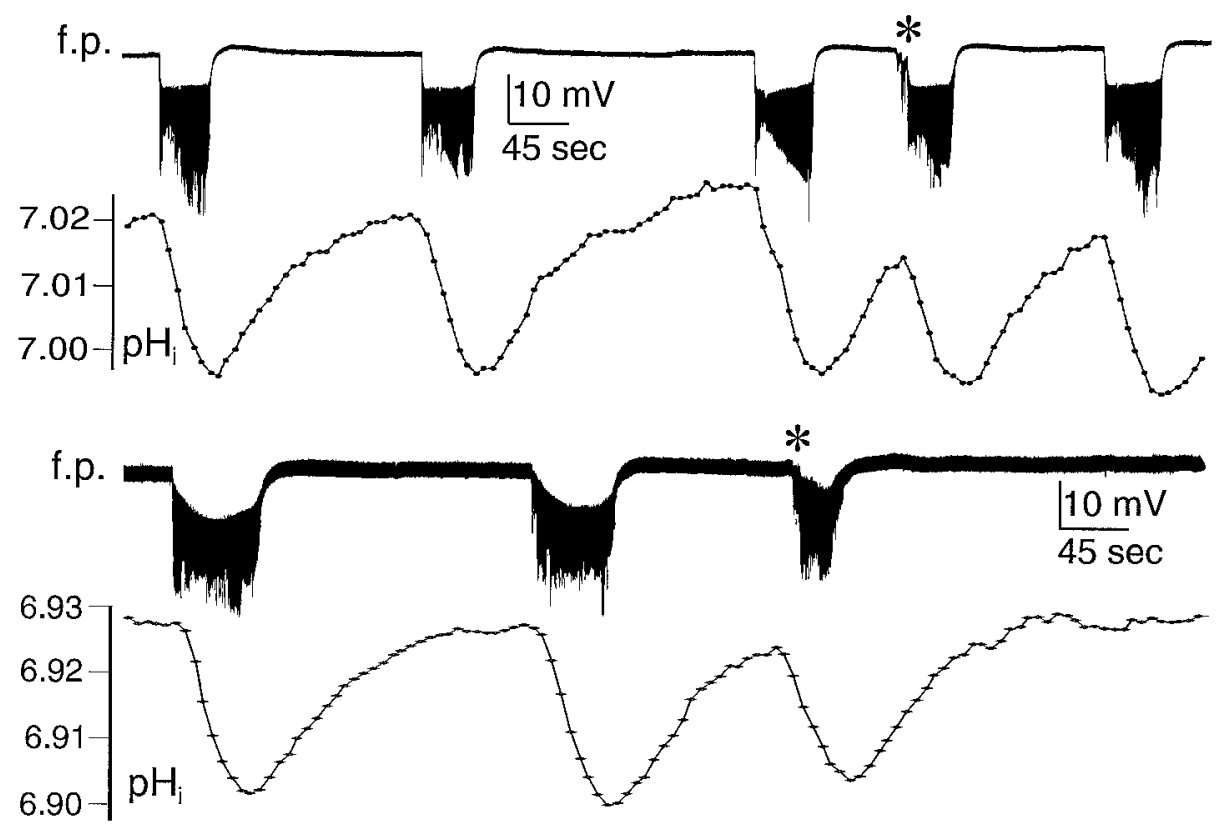

In most slices (80\%) that developed spontaneous field bursts, the burst duration and the interval between bursts were stable throughout the experiment $(\sim 2 \mathrm{hr})$. The periodicity of these field bursts correlated with the observed $\mathrm{pH}_{\mathrm{i}}$ changes. When $\mathrm{pH}_{\mathrm{i}}$ decreased to a certain value, the field bursts stopped. The recovery to a certain value coincided with the initiation of the next field burst. In some slices (20\%), however, an occasional spontaneous field burst started before the $\mathrm{pH}_{\mathrm{i}}$ had returned to the expected level. In these instances the duration of that particular "early" field burst was shorter than that of the regular recurring spontaneous bursts (Fig. 2). This suggests that reaching a particular level of intracellular acidification is correlated with the termination of the field burst.

To test this observation in a more controlled manner, we initiated field bursts with antidromic stimulation. After recording several consecutive spontaneous field bursts, one single antidromic stimulus was applied. When this stimulation was administered within $20 \mathrm{sec}$ after a spontaneous field burst, only a short burst of population spikes followed the stimulation. However, when the stimulation was applied in the middle of the interval between field bursts, it evoked a field burst. These evoked field bursts were of shorter duration than the regularly occurring field
Figure 3. Field bursts initiated by antidromic stimulation vary in duration. $A$, After recording several consecutive spontaneous field bursts, one single antidromic stimulation was applied. Shortly after $(<20 \mathrm{sec})$ a spontaneous field burst, antidromic stimulation elicited only a brief burst of population spikes $(1,2)$. When stimulation was applied in the middle of the interval between field bursts, it evoked a field burst (3). The later the application of the stimulation, the longer the duration of the evoked field burst $(3,4)$. B, Expanded views of the population spikes (marked with 1-4) evoked by antidromic stimulation are shown.
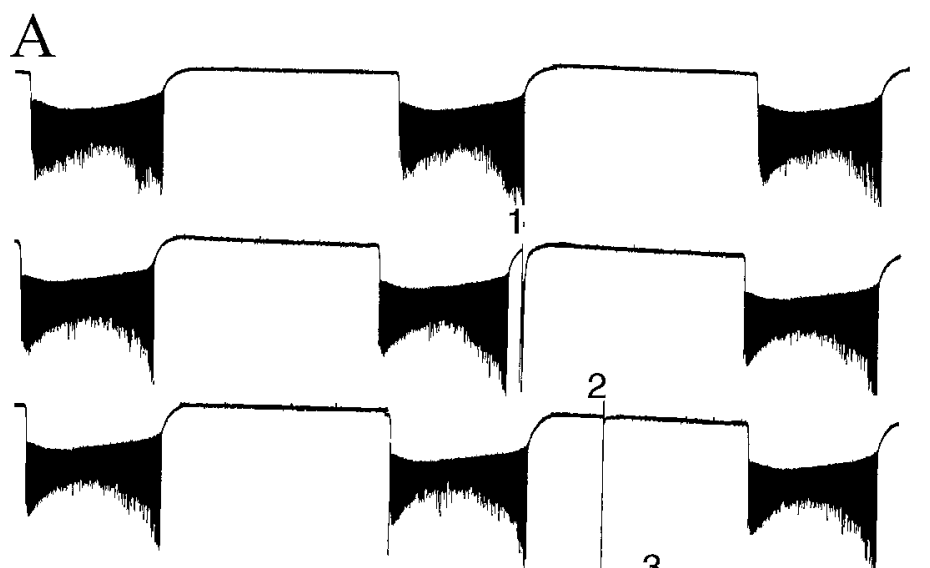

B
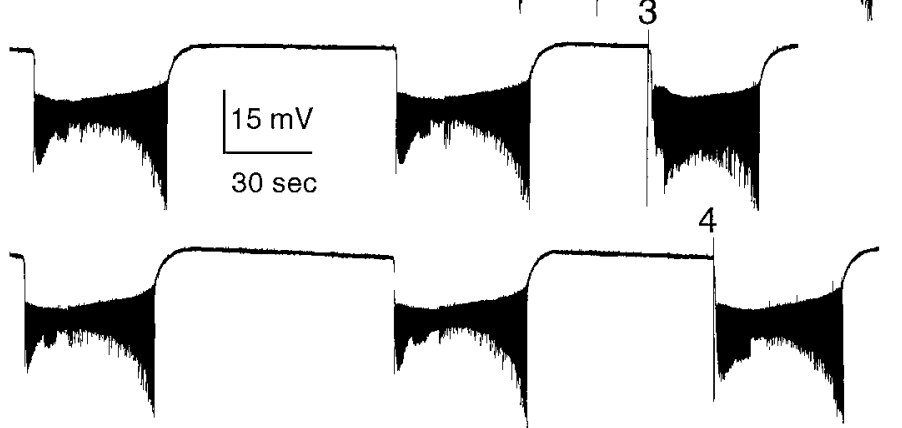
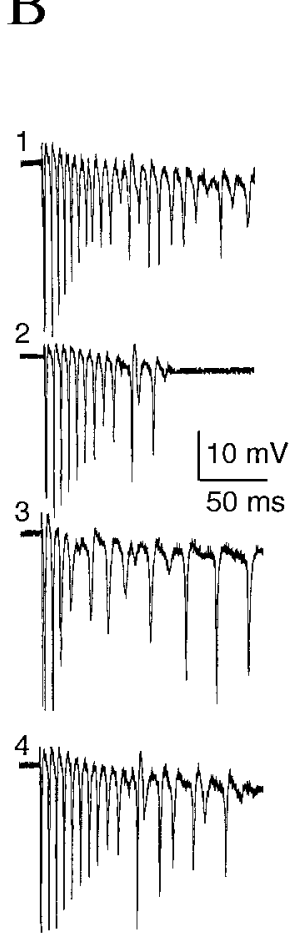

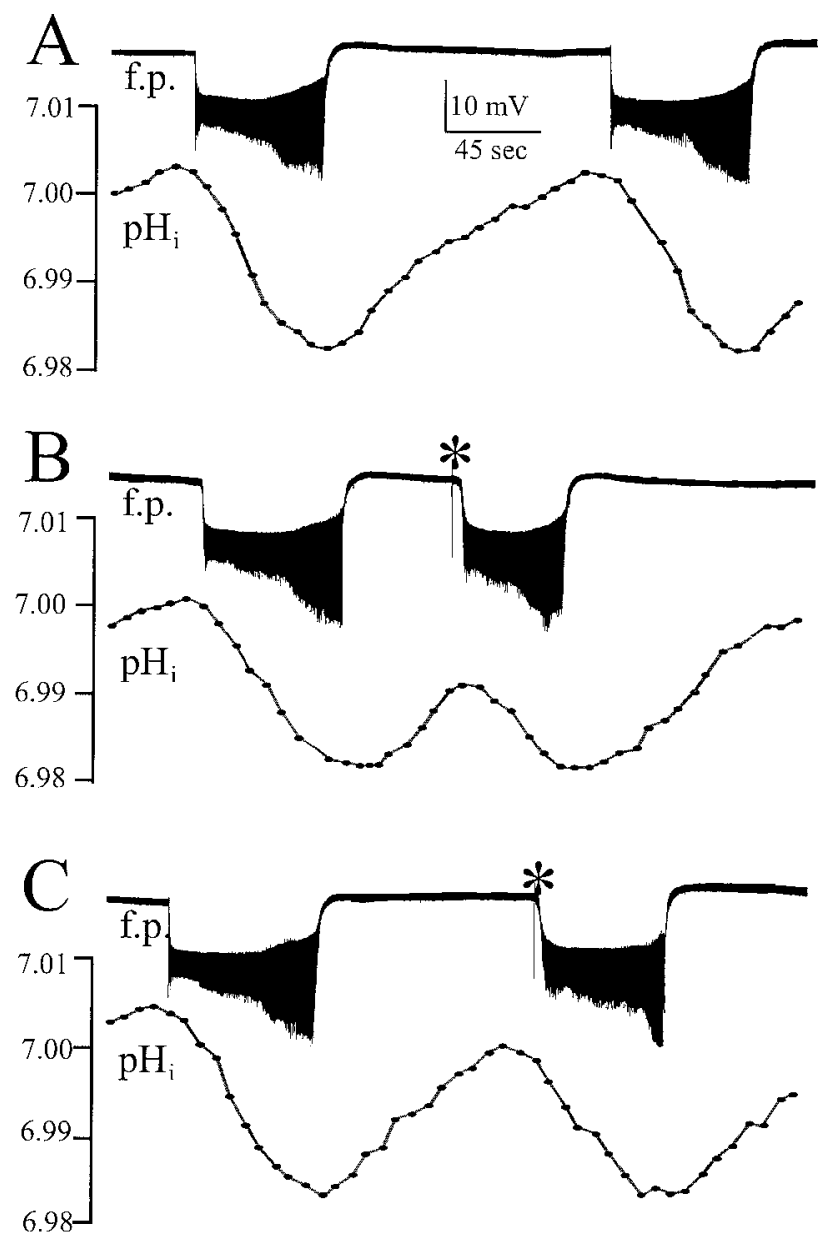

Figure 4. Correlation of $\mathrm{pH}_{\mathrm{i}}$ with the duration of field bursts initiated by antidromic stimulation. $A$, Spontaneous field bursts (top) and the associated $\mathrm{pH}_{\mathrm{i}}$ changes (bottom) are shown. $B, C$, Antidromic stimulation (*) before $\mathrm{pH}_{\mathrm{i}}$ had recovered to the expected level could evoke field bursts that terminated when $\mathrm{pH}_{\mathrm{i}}$ had again reached its lowest value in that slice.

bursts. When the stimulus was applied later, near the end of the interval between field bursts, it elicited a longer duration burst. When stimulation was applied just before the predicted spontaneous onset of field bursts, it evoked a field burst with a duration as long as that of the spontaneous bursts (Fig. $3 ; n=6$ ). The initial population spike evoked by antidromic stimulation at any time showed the same amplitude as the one during the spontaneous field bursts (Fig. 3B). Simultaneous measurement of $\mathrm{pH}_{\mathrm{i}}$ revealed that the duration of the stimulation-induced field bursts correlated with $\mathrm{pH}_{\mathrm{i}}$ changes (Fig. 4). The $\mathrm{pH}_{\mathrm{i}}$ was lowest just after the termination of a field burst, and stimulation at this point only evoked multiple spikes but no field bursts (data not shown). When the $\mathrm{pH}_{\mathrm{i}}$ had recovered to $\sim 50 \%$ of the total expected change, antidromic stimulation evoked a field burst that terminated when $\mathrm{pH}_{\mathrm{i}}$ had again reached its lowest value in that slice. The more the $\mathrm{pH}_{\mathrm{i}}$ had recovered, the longer was the duration of the antidromically evoked field burst ( $n=3$ slices).

To test the relationship between burst duration and $\mathrm{pH}_{\mathrm{i}}$, we altered the burst duration by changing the bath temperature. Measurements were taken after the temperature had stabilized for $20 \mathrm{~min}$ at each point. Decreasing the bath temperature below $30^{\circ} \mathrm{C}$ increased the duration of field bursts (Fig. $5 A ; n=5$ ). Increasing the bath temperature above $30^{\circ} \mathrm{C}$ shortened the dura-
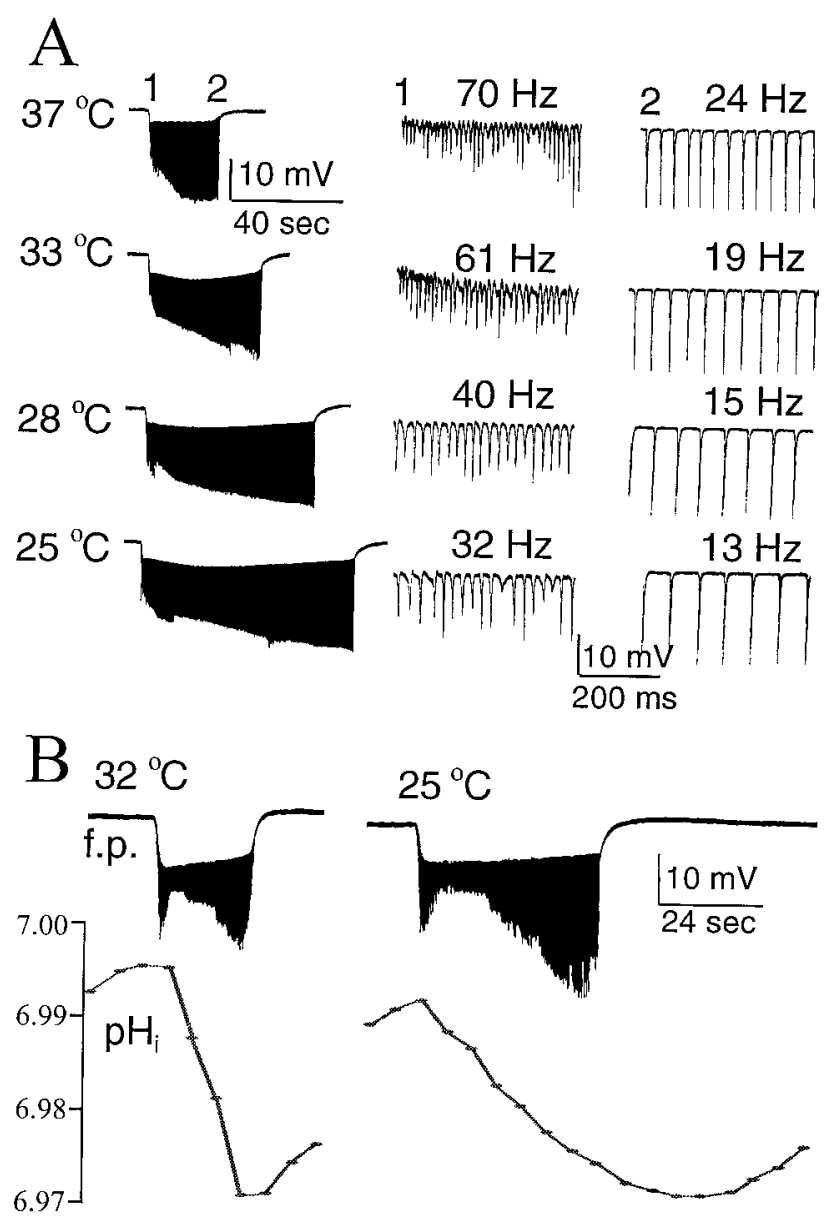

Figure 5. Temperature-dependent changes in burst duration, spike frequency, and acidification rate. $A$, Decreases in the bath temperature increased the burst duration (left) and slowed the spike frequency (middle, right). $B$, Lowering the bath temperature also slowed the acidification rate (bottom) during field bursts (top).

tion of the field bursts. For example, the duration of the field burst induced at $35^{\circ} \mathrm{C}$ was half of that induced at $25^{\circ} \mathrm{C}$. Also associated with the temperature changes were changes in spiking frequency within the field burst. Within all field bursts, the population spike frequency was highest at the beginning of the field burst and gradually decreased toward its termination. At higher temperatures, the spiking frequency was faster throughout the field burst. The rate of intracellular acidification also varied with bath temperature (Fig. $5 B ; n=3$ ). At higher temperatures the $\mathrm{pH}_{\mathrm{i}}$ acidified faster than at lower temperatures.

To study the interaction between the $\mathrm{pH}_{\mathrm{i}}$ and the field burst duration further, we altered the $\mathrm{pH}_{\mathrm{i}}$ and measured subsequent changes in the field burst duration. Intracellular acidification with a bath perfusion of 10 or $20 \mathrm{~mm}$ sodium propionate blocked spontaneous field bursts within minutes (Fig. $6 A ; n=10$ ). The spontaneous field bursts and $\mathrm{pH}_{\mathrm{i}}$ recovered after washout of the sodium propionate. Another agent that is widely used to modulate intracellular $\mathrm{pH}$ is ammonium chloride. $\mathrm{NH}_{4} \mathrm{Cl}$ is known to induce a transient intracellular alkalinization and a transient intracellular acidification on washout (Perez-Velazquez et al., 1994; de Curtis et al., 1998). The duration of the field bursts increased immediately after $3 \mathrm{mM} \mathrm{NH}_{4} \mathrm{Cl}$ was added. Washout of $\mathrm{NH}_{4} \mathrm{Cl}$, producing transient intracellular acidification, blocked the field bursts (Fig. $6 B ; n=5$ ). The $\mathrm{pH}$ of the extracellular 

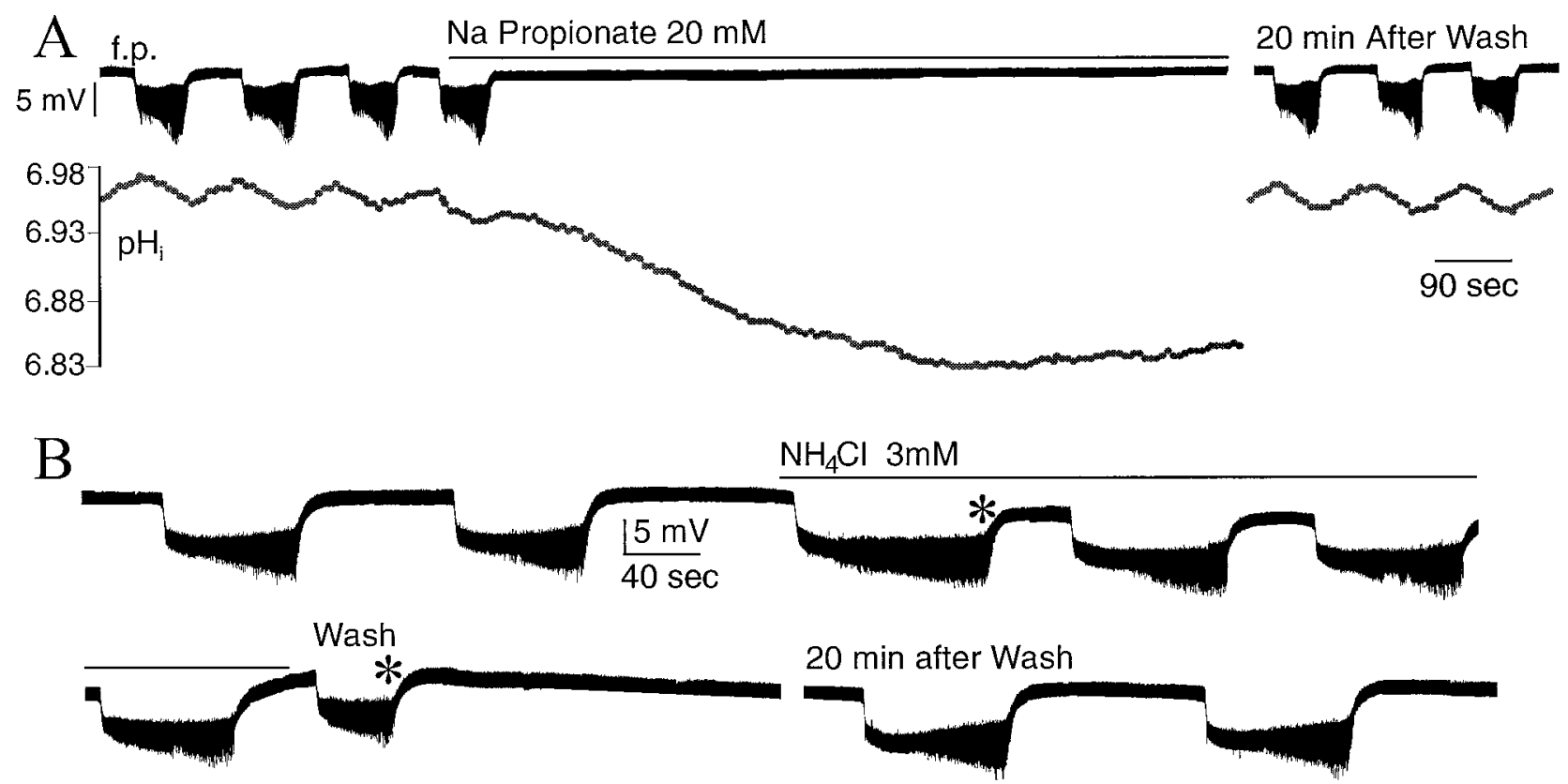

Figure 6. Manipulation of $\mathrm{pH}_{\mathrm{i}}$ alters the duration of the field bursts. $A$, Top, Perfusion with the weak acid sodium propionate (20 mu) blocked field bursts, which recovered after washout. Bottom, Blockade of field bursts by sodium propionate was associated with intracellular acidification. The $\mathrm{pH}_{\mathrm{i}}$ returned to previous levels after washout. $B$, Top, Perfusion with the weak base $\mathrm{NH}_{4} \mathrm{Cl}(3 \mathrm{mM})$ increased the duration of field bursts immediately (marked by ${ }^{*}$ ) after $\mathrm{NH}_{4} \mathrm{Cl}$ was added to the perfusion. Bottom, Washout of $\mathrm{NH}_{4} \mathrm{Cl}$ blocked field bursts quickly (marked by *). Spontaneous field bursts recovered after prolonged washout.

medium was not changed by addition of the sodium propionate or ammonium chloride ( $\mathrm{pH} 7.38 ; n=15)$.

Another simple way to change $\mathrm{pH}_{\mathrm{i}}$ is to change the $\mathrm{pH}$ of the extracellular medium. Decreasing external $\mathrm{pH}$ will acidify the intracellular space (Roos and Boron, 1981). To change $\mathrm{pH}_{\mathrm{i}}$ locally, we applied acidic medium locally $\left(0 \mathrm{Ca}^{2+}\right.$ and $8 \mathrm{mM} \mathrm{K}^{+}$ medium, $\mathrm{pH}$ 6.0) to the cell body layer of the dentate gyrus using a blunt delivery pipette. The epileptiform activity recorded from three electrodes placed at an interval of $300 \mu \mathrm{m}$ along the dorsal aspect of the dentate gyrus (Fig. $7 A$ ) was highly synchronized. Although the onset of field bursts showed a delay $(<1 \mathrm{sec})$, the termination of field bursts at the three sites was well synchronized. Local application of acidic medium to the middle site (site 2) blocked the seizure activity at that location and desynchronized the other two sites. Removal of the delivery pipette allowed recovery of the bursts at the site of application and resynchronization of the dentate gyrus (Fig. $7 B ; n=5$ ). If the acidic medium was applied after the initiation of a field burst, it terminated that burst within seconds (Fig. $7 C ; n=3$ ). If the acidic medium was applied before the initiation, it delayed the initiation of the field burst, and the subsequent field burst was very short (Fig. $7 D ; n=$ 5). Local application of control medium ( $\mathrm{pH}$ 7.38) had no effect on the duration and synchronization of field bursts $(n=3)$.

\section{DISCUSSION}

For the first time, to our knowledge, dynamic activity-dependent $\mathrm{pH}_{\mathrm{i}}$ changes have been recorded during epileptiform activity. Field bursts of the granule cells in the dentate gyrus were associated with intracellular acidification. After the termination of the field burst, the intracellular $\mathrm{pH}$ slowly recovered. The data also show a direct relationship between the level of intracellular acidification and the duration of the field bursts. It appears that acidification to a certain threshold results in termination of epileptiform discharges. Because many cellular processes are $\mathrm{pH}$ - sensitive, intracellular acidification may be an important restraining force to prevent neuronal activity from reaching levels that threaten the integrity of normal brain function (Ransom, 1992). In addition, these data suggest that modulation of $\mathrm{pH}$ homeostasis or $\mathrm{pH}$-sensitive targets may provide new therapeutic opportunities for clinically intractable seizures.

Previous studies have suggested several possible mechanisms for seizure termination. One possible mechanism is that elevated extracellular potassium causes a depolarization blockade of spike generation in neurons (Bragin et al., 1997). Alternatively, neuronal excitability may be blocked by enhanced activity of the $\mathrm{Na}^{+} / \mathrm{K}^{+}$ATPase (Konnerth et al., 1986). Our data demonstrate that neuronal excitability is not reduced at the end of the field bursts, when the population spikes are still as large as (or larger than) that at the beginning of the burst, and after the end of the field bursts, when antidromic stimulation can evoke multiple large-amplitude population spikes. There is evidence that extracellular potassium changes may be involved in seizure initiation and spread (Yaari et al., 1986), but termination of seizures, or determination of seizure duration, does not appear to be directly related to extracellular potassium levels.

Another candidate mechanism for seizure termination is inactivation of sodium channels. If termination of synchronized seizure activity was caused by widespread sodium channel inactivation, we would predict that stimulation just after a seizure would elicit no (or only a small) amplitude response. We found that just after the termination of a field burst, antidromic stimulation still evoked multiple spikes that showed the same amplitude as the spontaneous field bursts. Finally, it has been suggested that pacemaker failure is responsible for the termination of ictal episodes in the low- $\mathrm{Mg}^{2+}$ model of epilepsy in the neocortex (Wong and Prince, 1990). Local application of an NMDA receptor antagonist blocked rapid propagation across treated areas and resulted 

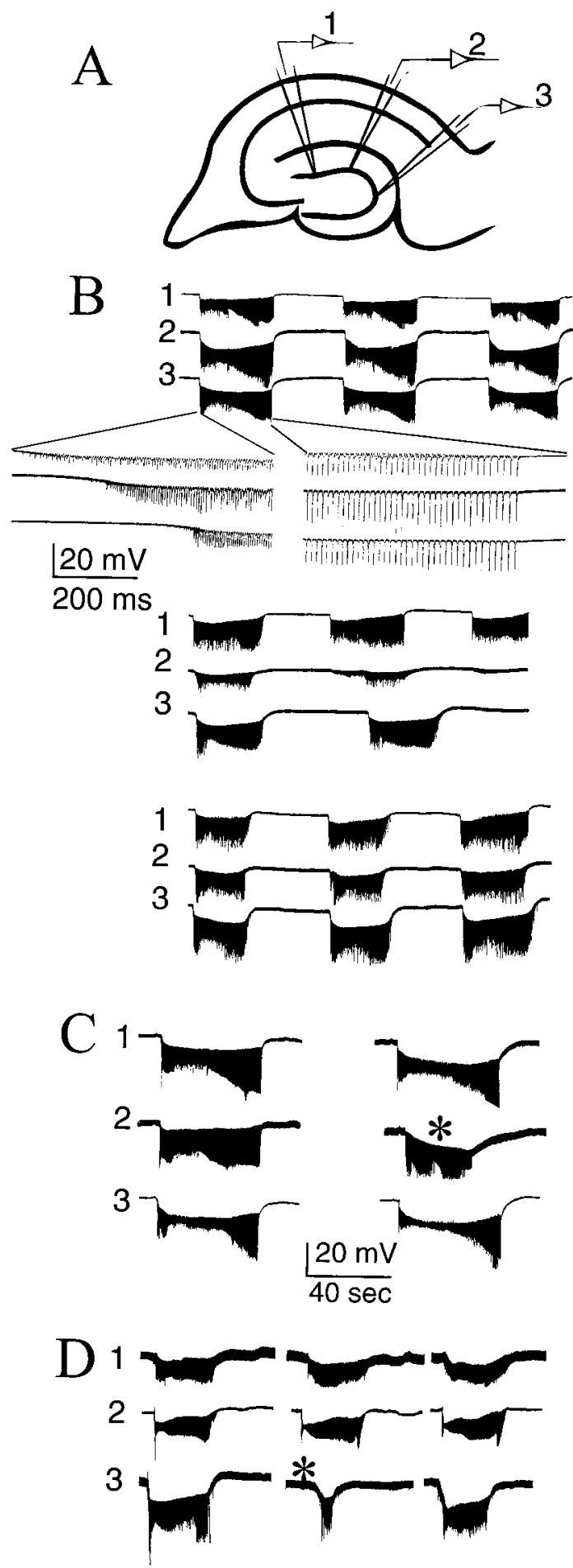

Figure 7. The duration of the field bursts in the dentate gyrus is altered by local $\mathrm{pH}$ acidification. $A$, Three extracellular electrodes (1-3) were placed $300 \mu \mathrm{m}$ apart along the dorsal aspect of the dentate gyrus. B, Top, Spontaneous field bursts were highly synchronized in the whole dentate gyrus. Inset, A faster timescale shows that the onset of field bursts at the three recording sites had a small delay but that the termination of bursts at these sites was completely synchronized. Middle, This set of chart recordings shows that local application of acidic medium near the middle electrode blocked the field burst at that location and disrupted the synchronization between sites 1 and 3. Bottom, The effect of local acidic medium was reversible. $C$, When acidic medium was locally applied after the onset of one field burst $(*)$, it blocked that field burst quickly. $D$, If the acidic medium was applied before the onset of one field burst $\left(^{*}\right)$, it delayed the onset and stopped it early. in the emergence of spatially separate, independent pacemakers (Wong and Prince, 1990). In our study, local application of acidic medium blocked the synchronization in the dentate gyrus, suggesting a similar emergence of separated, independent pacemakers.

In the present study, activity-dependent intracellular acidification during seizure activity was recorded, but the molecular basis of the acidification was not determined. Prolonged synchronous neuronal activity may be expected to lower $\mathrm{pH}_{\mathrm{i}}$ via several mechanisms. These include the metabolic production of $\mathrm{CO}_{2}$ and lactate (Thomas and Meech, 1982; Siesj $\div$ et al., 1985), the net entry of acid through ligand- or voltage-gated channels (Kaila and Voipio, 1987; Chen and Chesler, 1992), and $\mathrm{Ca}^{2+}$-dependent processes (Meech and Thomas, 1977; Wang et al., 1994). Although the field bursts were induced in 0 added $\mathrm{Ca}^{2+}$ medium, the interstitial $\mathrm{Ca}^{2+}$ concentration may not be low enough to rule out the contribution of $\mathrm{Ca}^{2+}$ entry to the intracellular acidification process.

Our study suggests a novel explanation for seizure termination. Intense neuronal discharges during seizure activity result in gradual intracellular acidification. When $\mathrm{pH}_{\mathrm{i}}$ reaches a certain threshold, it inactivates cellular processes that are necessary for continuous neuronal firing. Recent work also suggests that seizure propagation in the nonsynaptic model is $\mathrm{pH}$ sensitive (Schweitzer et al., 1998). Metabolic acidosis, which would lower $\mathrm{pH}_{\mathrm{i}}$, may account for the mechanism of action of some antiepileptic treatments including carbonic anhydrase inhibitors (Velisek and Veliskova, 1994) and the ketogenic diet (Lennox, 1928). Although at this stage the specific pathway by which $\mathrm{pH}_{\mathrm{i}}$ could modulate seizure activity is not clear, our findings provide strong evidence for the hypothesis that $\mathrm{pH}_{\mathrm{i}}$ changes associated with neuronal activity can serve as a feedback signal to modulate such activity.

\section{REFERENCES}

Baukrowitz T, Tucker SJ, Schulte U, Benndorf K, Ruppersberg JP, Fakler B (1999) Inward rectification in KATP channels: a pH switch in the pore. ЕMBO J 18:847-853.

Bonnet U, Wiemann M, Bingmann D (1998) $\mathrm{CO}_{2} / \mathrm{HCO}_{3}^{-}$withdrawal from the bath medium of hippocampal slices: biphasic effect on intracellular $\mathrm{pH}$ and bioelectric activity of CA3-neurons. Brain Res 796:161-170.

Boyarsky G, Ganz MB, Sterzel RB, Boron WF (1988) pH regulation in single glomerular mesangial cells. I. Acid extrusion in absence and presence of $\mathrm{HCO}_{3}^{-}$. Am J Physiol 255:C844-C856.

Bragin A, Penttonen M, Buzsáki G (1997) Termination of epileptic afterdischarge in the hippocampus. J Neurosci 17:2567-2579.

Chen JC, Chesler M (1992) Extracellular alkaline shifts in rat hippocampal slice are mediated by NMDA and non-NMDA receptors. J Neurophysiol 68:342-344.

Chesler M, Kaila K (1992) Modulation of $\mathrm{pH}$ by neuronal activity. Trends Neurosci 15:396-402.

de Curtis M, Manfridi A, Biella G (1998) Activity-dependent pH shifts and periodic recurrence of spontaneous interictal spikes in a model of focal epileptogenesis. J Neurosci 18:7543-7551.

Gottfried JA, Chesler M (1994) Endogenous H+ modulation of NMDA receptor-mediated EPSCs revealed by carbonic anhydrase inhibition in rat hippocampus. J Physiol (Lond) 478:373-378.

Gutschmidt KU, Stenkamp K, Buchheim K, Heinemann U, Meierkord H (1999) Anticonvulsant actions of furosemide in vitro. Neuroscience 91:1471-1481.

Kaila K, Voipio J (1987) Postsynaptic fall in intracellular $\mathrm{pH}$ induced by GABA-activated bicarbonate conductance. Nature 330:163-165.

Kiss L, Korn SJ (1999) Modulation of N-type Ca2+ channels by intracellular $\mathrm{pH}$ in chick sensory neurons. J Neurophysiol 81:1839-1847.

Konnerth A, Heinemann U, Yaari Y (1986) Nonsynaptic epileptogenesis in the mammalian hippocampus in vitro. I. Development of seizurelike activity in low extracellular calcium. J Neurophysiol 56:409-423. 
Lennox WG (1928) Ketogenic diet in the treatment of epilepsy. N Engl J Med 199:74-75.

Meech RW, Thomas RC (1977) The effect of calcium injection on the intracellular sodium and $\mathrm{pH}$ of snail neurones. J Physiol (Lond) 265:867-879.

Muller-Borer BJ, Yang H, Marzouk SAM, Lemasters JJ, Cascio WE (1998) $\mathrm{pHi}$ and $\mathrm{pHo}$ at different depths in perfused myocardium measured by confocal fluorescence microscopy. Am J Physiol 275: H1937-H1947.

Pan E, Stringer JL (1996) Burst characteristics of dentate gyrus granule cells: evidence for endogenous and nonsynaptic properties. J Neurophysiol 75:124-132.

Perez-Velazquez JL, Valiante TA, Carlen PL (1994) Modulation of gap junctional mechanisms during calcium-free induced field burst activity: a possible role for electrotonic coupling in epileptogenesis. J Neurosci 14:4308-4317.

Qu Z, Zhu G, Yang Z, Cui N, Li Y, Chanchevalap S, Sulaiman S, Haynie H, Jiang C (1999) Identification of a critical motif responsible for gating of Kir2.3 channel by intracellular protons. J Biol Chem 274:13783-13789.

Ransom BR (1992) Glial modulation of neural excitability mediated by extracellular pH: a hypothesis. Prog Brain Res 94:37-46.

Roberts EL (1999) Using hippocampal slices to study how aging alters ion regulation in brain tissue. Methods 18:150-159.

Roos A, Boron WF (1981) Intracellular pH. Physiol Rev 61:296-434.

Schweitzer JS, Patrylo PR, Dudek FE (1992) Prolonged field bursts in the dentate gyrus: dependence on low calcium, high potassium, and nonsynaptic mechanisms. J Neurophysiol 68:2016-2025.

Schweitzer JS, Patrylo PR, Wang H (1998) Extracellular pH and nonsynaptic bursts in the rat dentate gyrus. Epilepsia 39[Suppl 6]:19-20.

Siesjö BK, von Hanwehr R, Nergelius G, Nevander G, Ingvar M (1985) Extra- and intracellular $\mathrm{pH}$ in the brain during seizures and in the recovery period following the arrest of seizure activity. J Cereb Blood Flow Metab 5:47-57.

Spencer SS, Spencer DD (1996) Implications of seizure termination location in temporal lobe epilepsy. Epilepsia 37:455-458.

Tang CM, Dichter M, Morad M (1990) Modulation of the $N$-methyl-D- aspartate channel by extracellular $\mathrm{H}+$. Proc Natl Acad Sci USA 87:6445-6449.

Thomas RC, Meech RW (1982) Hydrogen ion currents and intracellular $\mathrm{pH}$ in depolarized voltage-clamped snail neurones. Nature 1299:826-828.

Tombaugh GC, Somjen GG (1996) Effects of extracellular pH on voltage-gated $\mathrm{Na}+, \mathrm{K}+$ and $\mathrm{Ca} 2+$ currents in isolated rat CA1 neurons. J Physiol (Lond) 493:719-732.

Tomlinson FH, Anderson RE, Meyer FB (1992) Panoramic imaging of brain $\mathrm{pHi}$ and $\mathrm{CBF}$ during penicillin and metrazole induced status epilepticus. Epilepsy Res 13:49-58.

Tong CK, Chesler M (1999) Activity-evoked extracellular pH shifts in slices of rat dorsal lateral geniculate nucleus. Brain Res 815:373-381.

Tsien RY (1989) Fluorescent probes of cell signaling. Annu Rev Neurosci 12:227-253.

Velisek L, Veliskova J (1994) Anticonvulsant action of carbonic anhydrase inhibition. Sb Lek 95:161-171.

Velisek L, Dreier JP, Stanton PK, Heinemann U, Moshe SL (1994) Lowering of extracellular $\mathrm{pH}$ suppresses low-Mg2+-induced seizures in combined entorhinal cortex-hippocampal slices. Exp Brain Res 101:44-52.

Vincent AM, TenBroeke M, Maiese K (1999) Neuronal intracellular pH directly mediates nitric oxide-induced programmed cell death. J Neurobiol 40:171-184.

Wang GJ, Randall RD, Thayer SA (1994) Glutamate-induced intracellular acidification of cultured hippocampal neurons demonstrates altered energy metabolism resulting from $\mathrm{Ca} 2+$ loads. J Neurophysiol 72:2563-2569.

Wong BY, Prince DA (1990) The lateral spread of ictal discharges in neocortical brain slices. Epilepsy Res 7:29-39.

Yaari Y, Konnerth A, Heinemann U (1986) Nonsynaptic epileptogenesis in the mammalian hippocampus in vitro. II. Role of extracellular potassium. J Neurophysiol 56:424-438.

Zhan RZ, Fujiwara N, Tanaka E, Shimoji K (1998) Intracellular acidification induced by membrane depolarization in rat hippocampal slices: roles of intracellular Ca2+ and glycolysis. Brain Res 780:86-94. 